\title{
Heart rate variability is associated with disease severity in psychosis spectrum disorders
}

\author{
Beatrice R. Benjamin ${ }^{\mathrm{a}, \mathrm{b}}$, Mathias Valstad ${ }^{\mathrm{a}}$, Torbjørn Elvsåshagen ${ }^{\mathrm{a}, \mathrm{c}, \mathrm{d}}$, Erik G. Jönsson ${ }^{\mathrm{a}, \mathrm{e}}$, \\ Torgeir Moberget $^{\mathrm{a}, \mathrm{f}}$, Adriano Winterton ${ }^{\mathrm{a}}$, Marit Haram ${ }^{\mathrm{a}}$, Margrethe C. Høegh ${ }^{\mathrm{a}}$, \\ Trine V. Lagerberg ${ }^{\mathrm{a}}$, Nils Eiel Steen ${ }^{\mathrm{a}}$, Lars Larsen ${ }^{\mathrm{b}}$, Ole A. Andreassen ${ }^{\mathrm{a}, \mathrm{g}}$, Lars T. Westlye ${ }^{\mathrm{a}, \mathrm{f}, \mathrm{g}}$, \\ Daniel S. Quintana ${ }^{a, g, *}$ \\ a NORMENT, Division of Mental Health and Addiction, University of Oslo, and Oslo University Hospital, Oslo, Norway \\ ${ }^{\mathrm{b}}$ Department of Psychology and Behavioural Sciences, Aarhus University, Aarhus, Denmark \\ ' Department of Neurology, Division of Clinical Neuroscience, Oslo University Hospital, Oslo, Norway. \\ ${ }^{\mathrm{d}}$ Institute of Clinical Medicine, University of Oslo, Oslo, Norway. \\ ${ }^{\mathrm{e}}$ Centre for Psychiatric Research, Department of Clinical Neuroscience, Karolinska Institutet \& Stockholm Health Care Services, Stockholm Region, Stockholm, Sweden \\ ${ }^{\mathrm{f}}$ Department of Psychology, University of Oslo, Oslo, Norway \\ ${ }^{\mathrm{g}}$ KG Jebsen Centre for Neurodevelopmental Disorders, University of Oslo, Oslo, Norway
}

\section{A R T I C L E I N F O}

\section{Keywords:}

Heart rate variability

Schizophrenia

Bipolar disorder

Psychosis

\begin{abstract}
A B S T R A C T
While a growing literature links cardiac autonomic dysregulation to a variety of psychiatric disorders, the relationship between cardiac autonomic functioning and specific symptoms in schizophrenia (SZ) and bipolar disorder (BD) remains elusive. Thus, we investigated heart rate variability (HRV), a proxy for vagal activity, as a biological marker for symptom severity in patients with SZ and BD. HRV was calculated in 35 patients with SZ and 52 patients with BD, as well as in 149 healthy controls. In the patient groups, symptom severity and function were measured by the Positive and Negative Syndrome Scale (PANSS) and the Global Assessment of Functioning (GAF) scale. Results showed that HRV was significantly lower in both clinical groups compared to the healthy controls, with no significant HRV differences between patient groups. PANSS general psychopathology scores, GAF symptom scores, and GAF function scores showed statistically significant associations with HRV across groups. These results suggest that disease severity is associated with autonomic dysfunction and that HRV may provide a potential biomarker of disease severity in SZ and BD.
\end{abstract}

\section{Introduction}

Schizophrenia (SZ) and bipolar disorder (BD) are severe psychiatric disorders, with lifetime risks of 1-2\% (Pedersen et al., 2014), often causing substantial personal, societal, and economic burdens (Knapp et al., 2004; Woods, 2000). Current diagnostic systems (ICD-10 and DSM-5) classify SZ and BD as separate disorders, yet evidence suggests that they share a number of fundamental features, such as phenomenological expression (Krabbendam et al., 2004), genetic liability (Bramon and Sham, 2001; Lichtenstein et al., 2009), and cognitive deficits (Simonsen et al., 2009). These findings have led to the proposal of a unitary model of psychosis, where BD and SZ are conceptualized as lying on a continuum (Guloksuz and Van Os, 2018).

Patients with severe mental disorders have considerably reduced life expectancy (Laursen, 2011). This has been linked to cardiovascular diseases (CVD) (Hennekens et al., 2005; Weiner et al., 2011), and disturbed autonomic functioning may represent an important risk factor for such diseases (Thayer et al., 2010). Supporting this hypothesis, cardiac autonomic dysregulation has been associated with a variety of psychiatric disorders, including SZ, BD, anxiety disorders, and depressive disorders (Alvares et al., 2016). Of note, such dysregulation is not only linked with elevated CVD risk, but is also associated with increased psychophysiological stress, impaired capacity to modulate cognitive activity, diminished ability for adaptive emotion- and self-regulation, social dysfunction, and decreased psychological flexibility (Appelhans and Luecken, 2006; Holzman and Bridgett, 2017; Koval et al., 2013; Porges, 2011; Thayer and Lane, 2000).

Cardiac autonomic activity can be estimated non-invasively through the calculation of heart rate variability (HRV). HRV refers to the beatto-beat variation in heart rate, which approximates autonomic control

\footnotetext{
* Corresponding author at: NORMENT, Division of Mental Health and Addiction, University of Oslo, and Oslo University Hospital, Oslo, Norway.

E-mail address: daniel.quintana@medisin.uio.no (D.S. Quintana).
} 
of the heart rate (Berntson et al., 1997). The link between the autonomic nervous system and the cardiovascular system is largely directed by the central autonomic network (Benarroch, 1993), which serves as a regulatory system for the autonomic influences on heart rate. The central autonomic network is composed of a distributed network of brain areas including prefrontal cortical, limbic, and brainstem regions. The activity across these neural structures produce the output of the central autonomic network that is transmitted to the sinoatrial node, which is the heart's pacemaker. Decreased HRV, which is indicative of reduced parasympathetic nervous system activity (Akselrod et al., 1981), has been linked to increased cardiometabolic risk (Kemp and Quintana, 2013) and maladaptive response to stressors in the environment (Thayer and Lane, 2000). Moreover, the vast majority of research on HRV generally reports higher HRV in healthy individuals compared to patients with mental illnesses (Alvares et al., 2016).

Evidence suggests that patients with SZ and BD exhibit chronic reductions in HRV, which have been linked to disease severity (Clamor et al., 2016; Faurholt-Jepsen et al., 2017; Quintana et al., 2016b). However, due to study limitations with small sample sizes as well as inconclusive findings, the association between HRV and specific symptoms in these disorders remains unclear. Thus, this study aims to explore differences in HRV between patients with SZ, BD and healthy controls, and identify cardiac autonomic correlates of symptoms in the patient groups.

\section{Methods and materials}

\subsection{Participants}

All participants (total $n=236$; patient $n=87$; healthy control $n=149$; Table 1 ) were recruited as part of the Thematically Organized Psychosis (TOP) study. The study has been approved by the Regional Committee for Medical Research Ethics (REK South East) and the Norwegian Data Inspectorate. After receiving information regarding the study, participants signed a consent form emphasizing the voluntary nature of the study and the opportunity to withdraw at any time. All patients were referred to the TOP study by their clinicians from inpatient and out-patient clinics from psychiatric units at the four major hospitals in Oslo. Healthy controls were drawn from a randomly selected community sample using government statistical records (Statistisk sentralbyrå, http://ssb.no) from the same catchment area as the patient sample.

Sample size requirements were calculated according the power analysis for a univariate ANOVA and follow-up $t$-tests. Power analysis was obtained using G*Power (Faul et al., 2007). For a univariate ANOVA to reliably (with a probability greater than $80 \%$ ) detect an effect size of $\eta^{2} \mathrm{p}=0.06$, which is considered a medium effect size (Cohen, 1988), the total required sample size distributed in 3 groups was 156, indicating that the current sample size of 236 is sufficient. Case-control HRV studies of psychosis spectrum disorders are associated with large effect sizes, with a median reported effect size from 44 studies of $d=0.81$ (Quintana, 2016). To detect an effect size difference of $d=0.81$ with $80 \%$ statistical power, a sample size of at least 27 is required per group. To detect a medium-sized Pearson's $r$ coefficient $(r=0.3)$ to examine the relationship between HRV and clinical outcomes (Cohen, 1988) with $80 \%$ power, a sample size of at least 85 participants is required.

Upon inclusion, all patients underwent a structured clinical Interview for Axis I disorders (SCID; First and Gibbon, 2004) by trained clinicians to confirm diagnosis of either a schizophrenia spectrum disorder or a bipolar spectrum disorder. Healthy controls were screened with the Primary Care Evaluation of Mental Disorders (PRIME-MD; Spitzer et al., 1994). Exclusion criteria for all participants were a history of moderate or severe head injury, neurological disorder, IQ < 70 , insufficient understanding of a Scandinavian language, and age outside the range of 18 to 65 years at time of inclusion. In addition to the general exclusion criteria, healthy controls were excluded if they had used cannabis in the last three months, had a drug dependency, if they or any first-degree relatives had a lifetime history of severe psychiatric disorder, and if they had a history of medical problems thought to interfereinterferei with brain function. The sample in the present study consisted of 149 healthy controls and 87 patients with a DSM-IV diagnosis of a schizophrenia spectrum disorder (total $n=35$; schizophrenia $n=20$; schizophreniform disorder $\mathrm{n}=3$; schizoaffective disorder $\mathrm{n}=3$; other psychosis $n=9$ ) or a bipolar spectrum disorder (total $n=52$; bipolar I disorder $n=28$; bipolar II disorder $n=24$ ).

Table 1

Demographic and clinical variables

\begin{tabular}{|c|c|c|c|c|c|c|c|}
\hline Group & $\mathrm{HC}(\mathrm{n}=149)$ & $\mathrm{SZ}(\mathrm{n}=35)$ & $\mathrm{BD}(n=52)$ & $F(d f)$ & $p$ & $\eta^{2} \mathrm{p}$ & $\chi^{2}$ \\
\hline BMI $^{\mathrm{b}}$ & $25.0(4.17)$ & $25.3(6.27)$ & $26.0(4.9)$ & $0.96(2,224)$ & 0.39 & 0.01 & - \\
\hline $\operatorname{Sex}(M / F)^{f}$ & $73 / 73$ & $16 / 19$ & $21 / 31$ & - & 0.48 & - & 1.46 \\
\hline Daily nicotine intake $(\mathrm{Y} / \mathrm{N})^{\mathrm{d}}$ & - & $17 / 18$ & $16 / 35$ & - & 0.11 & - & 2.6 \\
\hline Patient status (IP/OP/NP) & - & $7 / 28 / 0$ & $3 / 47 / 2$ & - & 0.07 & - & 5.29 \\
\hline DUDIT total score ${ }^{e}$ & - & $4.21(6.95)$ & $2.31(5.08)$ & $2.09(1,82)$ & 0.15 & 0.02 & - \\
\hline PANSS negative symptoms ${ }^{\mathrm{d}}$ & - & $15.03(5.9)$ & $9.69(3)$ & $30(1,84)$ & $<0.001$ & 0.26 & - \\
\hline PANSS general symptoms & - & $31.6(7.7)$ & $25.6(5.4)$ & $18(1,85)$ & $<0.001$ & 0.17 & - \\
\hline GAF symptom score & - & $55.1(13.6)$ & $60.8(9.1)$ & $5.42(1,85)$ & 0.02 & 0.06 & - \\
\hline GAF function score ${ }^{\mathrm{d}}$ & - & $52.3(16.3)$ & $78.5(130.7)$ & $7.17(1,84)$ & 0.01 & 0.08 & - \\
\hline YMRS score & - & $2.37(3.6)$ & $2.56(3.4)$ & $0.06(1,85)$ & 0.81 & 0.001 & - \\
\hline
\end{tabular}

Note: Group values represent means with standard deviations in parentheses, or number of participants in each group. HC = healthy control; SZ $=$ Schizophrenia, $\mathrm{BD}=$ Bipolar disorder, $\mathrm{BMI}=$ body mass index; $\mathrm{IP}=$ inpatient; $\mathrm{OP}=$ outpatient; $\mathrm{NP}=$ non-patient; DUDIT = Drug Use Disorders Identification Test; HF $\mathrm{HRV}=$ High frequency heart rate variability; PANSS = positive and negative syndrome scale; GAF = global assessment of functioning; YMRS = Young mania rating scale.

${ }^{\text {a }}$ HC group $n=135$.

b $\mathrm{HC}$ group $n=142$, BD group $n=50$

c $\mathrm{SZ}$ group $=32, \mathrm{BD}$ group $=45$.

$\mathrm{d}$ BD group $=51$.

e $\mathrm{SZ}$ group $=33, \mathrm{BD}$ group $=51$.

${ }^{\mathrm{f}}$ HC group $n=146$. 
In the patient groups, current severity of disease was assessed by the Positive and Negative Syndrome Scale (PANSS; Kay et al., 1987). The PANSS is a structured clinical interview that is comprised of three components: Positive symptoms, Negative symptoms, and General symptoms. The relationship between these three component scores and HRV in patient groups has been previously investigated to examine the association between disease severity in psychosis spectrum disorders and HRV (Quintana et al., 2016b). In addition to the PANSS, psychosocial functioning in patients was assessed with the Global Assessment of Functioning (GAF) scale, split version (Pedersen et al., 2007). The GAF assesses general symptom (GAF-S) and functioning (GAF-F) levels and covers a range of levels from good mental health to severe psychopathology. Strictly speaking, the GAF-F sub-score is an indirect measure of disease severity as it indexes day-to-day psychosocial functioning. Patients were also assessed with the Young Mania Rating Scale (YMRS), which is used to measure current hypomanic or manic symptom severity (Young et al., 1978). The Drug Use Disorders Identification Test (DUDIT; Hildebrand, 2015) and a measure of daily nicotine consumption (yes/no response) were also collected.

\subsection{Physiology data collection and analysis}

HRV data was reported in accordance with Guidelines for Reporting Articles on Psychiatry and Heart rate variability (GRAPH; Quintana et al., 2016a). Electrocardiography (ECG) was recorded during an electroencephalography (EEG) session with a $1000 \mathrm{~Hz}$ sampling rate, using BioSemi ActiveTwo hardware. A modified Lead-II configuration was used with two active $\mathrm{Ag} / \mathrm{AgCl}$ electrodes, placing the negative electrode on the right clavicle and the positive electrode on the left iliac crest. The hardware was connected to a stationary computer containing ActiView software (Cortech Solutions, Wilmington, NC, USA) where the electrode signal was graphically reproduced as a Lead-I ECG. All participants were instructed to refrain from caffeine for at least $1 \mathrm{~h}$ prior to assessment, and data was measured under similar environmental settings in the same laboratory.

The EEG experiment consists of an 80-min recording session encompassing different stimuli-related paradigms. The paradigms include a visual evoked potential (VEP) paradigm, a mismatch negativity (MMN) paradigm, a pre-pulse inhibition (PPI) paradigm, and a resting state EEG recording. Heart rate was continuously measured during all paradigms. For HRV evaluation, the MMN paradigm was chosen as this entails a so-called "vanilla task", which requires the participant to take part in a minimally-demanding task (Jennings et al., 1992). Paradoxically, a vanilla task may be less stressful than a traditional restingstate task, which could be perceived as "forced relaxation" (Farha and Sher, 1989). The participants were seated in a chair in front of a desk with a desktop computer for the full duration of the EEG-experiment. The MMN paradigm occurs 20 min into the session and lasts approximately $15 \mathrm{~min}$. Here, auditory pitch stimuli were delivered to the participants through earphones, while they were instructed to read a magazine and not pay any particular attention to the auditory stimuli.

Interbeat intervals (IBIs), which were identified via the $\mathrm{R}$ peaks of ECG complexes, were retrieved via ActiView. Data processing and analysis followed Task Force (Camm et al., 1996) recommendations and was carried out using Kubios HRV software (version 3.0.0). Appropriate handling of artifacts in IBI data is crucial to get accurate results from HRV analysis (Berntson and Stowell, 1998; Quintana and Heathers, 2014), consequently all data were visually inspected to detect any nonsinus or movement events. Any detected artifact was manually checked, with the rater blind to participant group. The first $5 \mathrm{~min}$ of data recordings were discarded for all participants to account for any differences in habituation to the MMN paradigm and exclude setting-related disturbances (e.g., adjustment of seating position). Then, the first full $5 \mathrm{~min}$ period without artifacts was selected from the remaining $10 \mathrm{~min}$ sample to avoid potential errors associated with artifacts and artifact correction (Berntson and Stowell, 1998). Absolute high frequency HRV
(HF HRV; 0.15-0.40 Hz) almost exclusively contains contributions from parasympathetic activity (Berntson et al., 1997), and has been found to be highly correlated with other measures of PNS activity (e.g., root mean square of successive differences; RMSSD) (Berntson et al., 1997). Absolute HF HRV values were log-transformed to better approximate a normal distribution.

\subsection{Statistical analysis}

Statistical analyses were conducted in the R statistical environment (version 3.6.1), using the base statistics package (version 3.6.1), 'jmv' package (version 0.9.6.1) (Selker et al., 2018), 'walrus' R package (version 1.0.3) (Love and Mair, 2018), 'meta' R package (version 4.9-7) (Schwarzer, 2019), and the BayesFactor package (version 0.9.12-4.2) (Morey et al., 2018). Univariate analyses of variance (ANOVA) were performed to test for group (SZ, BD, HC) differences in age and body mass index (BMI). Chi-squared tests were performed to assess differences in the proportions of males and females in each group along with differences in nicotine intake and current treatment status (inpatient, outpatient, no treatment) between SZ and BD patients.

To examine whether medication had any potential impact on HRV, all patients receiving psychopharmacological treatment were divided into two groups reflecting medication characteristics; 1) patients taking medications with known anticholinergic effects, and 2) patients taking medications without any known anticholinergic effects. Medications classed as "anticholinergic" included antipsychotics associated with high muscarinic affinity (i.e., olanzapine, clozapine and quetiapine), as these are known to affect parasympathetic nervous system modulation (Alvares et al., 2016; Huang et al., 2013). Additional medications classed as anticholinergic included antipsychotics associated with tachycardia risk (i.e., aripriprazol, paliperidone and risperidone), which influence heart contractions and increase heart rate (Hattori et al., 2018; Tzimos et al., 2008), mood stabilizers (e.g., lithium, lamotrigine), and antidepressants known to influence HRV (i.e., tricyclic antidepressants, paroxetine) (Alvares et al., 2016; Kemp et al., 2010). An independent-samples $t$-test was conducted to compare HRV for patients in each medication group.

Univariate ANOVAs were conducted to investigate differences in HRV between all groups (SZ, BD, HC) along with differences in clinical variables (PANSS and GAF) between patient groups (SZ, BD), with pairwise comparisons conducted to follow-up any significant differences and Bonferroni corrections applied for multiple comparisons. Robust statistical tests were applied using the 'walrus' R package to account for the potential effects of outliers and non-normally distributed data (Wilcox, 2011), in which the bottom and top $10 \%$ of values are removed. To assess the relative evidence for the null hypothesis to the alternative hypothesis, a Bayesian ANOVA (Quintana and Williams, 2017) with posthoc tests was conducted in JASP (version 0.9; JASP team), using a fixed effects $r$ scale prior of 0.5 .

For more precise effect size estimates, data from the present study was meta-analytically synthesized with data from our prior study (Quintana et al., 2016b). A random-effects model was used with a DerSimonian-Laird estimator to calculate $\tau^{2}$, which provides an estimate of the total amount of heterogeneity. $I^{2}$ was also calculated, which is the percentage of total variability due to heterogeneity. In the event of a non-significant difference in the meta-analysis, meta-analytic Bayes factors were calculated to examine the relative evidence for an alternative and null hypothesis, using a standard $t$-test Cauchy prior (i.e., $r$ scale $=1$ ) (Rouder et al., 2009).

Lastly, bivariate correlational analyses were performed to determine linear relationships between $\mathrm{HRV}$ and disease severity measures (PANSS and GAF) in SZ and BD using Pearson's correlation coefficient. To reduce the risk of false positives from conducting a group of seven significance tests, false discovery rate (FDR) $p$-value thresholds were calculated for these correlation coefficients. To assess the impact of covariates on the relationship between clinical variables and HRV, we 

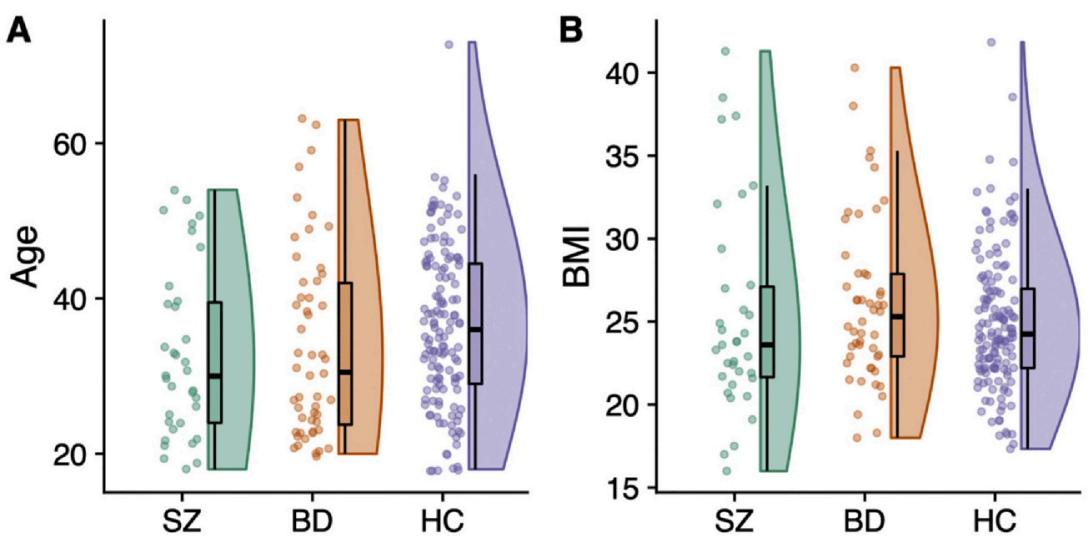

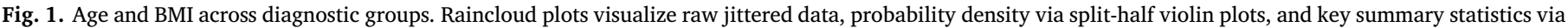
overlaid boxplots. SZ $=$ Schizophrenia; $\mathrm{BD}=$ Bipolar disorder; $\mathrm{HC}=$ Healthy control.

fitted linear regression models with HRV as dependent variable and each of the disease severity measures, along with age, BMI, sex, anticholinergic medication status, daily nicotine intake, and drug problem risk (i.e., total DUDIT score) as independent variables. The alpha thresholds for the seven disease severity coefficients were also FDRcorrected. The R script used to generate results is available at https:// osf.io/fxhra/.

\section{Results}

\subsection{Sample characteristics}

Table 1 and Fig. 1 display demographic characteristics of patient groups (SZ and BD) and healthy controls (HC). There was no significant main effect of group on age $\left[\mathrm{F}(2,219)=2.07, p=0.13 ; \eta^{2} p=0.02\right]$ or $\mathrm{BMI}\left[\mathrm{F}(2,224)=0.96, p=0.39 ; \eta^{2} \mathrm{p}=0.01\right]$. Chi-squared tests revealed no significant difference in the proportion of males and females in the three groups $\left(\chi^{2}=1.46, p=0.48\right)$, and no significant difference in the proportions of treatment categories (i.e., inpatient, outpatient, no treatment) between the two patient groups $\left(\chi^{2}=5.29, p=0.07\right)$.

\section{2. $H R V$ and clinical characteristics}

Group differences in HRV and clinical variables (PANSS scores, GAF scores, and YMRS total score) are presented in Table 1, and in Fig. 2 using raincloud plots (Allen et al., 2019). Mean HRV was higher in the HC group (HF: $M=2.69, S D=0.47$ ) than in the SZ group (HF: $\mathrm{M}=2.21, \mathrm{SD}=0.76$ ) and $\mathrm{BD}$ group (HF: $\mathrm{M}=2.47, \mathrm{SD}=0.51$ ), with slightly higher mean levels in the BD group compared to the SZ group.

Welch's independent samples $t$-tests revealed no significant difference in HRV for patients taking antipsychotics with anticholinergic properties [ $t(37.6)=-1.1, p=0.27$, Cohen's $d=-0.27]$ compared to patients not taking medications with known anti-cholinergic properties or patients who consumed nicotine daily $[t(83.7)=0.8, p=0.4$, Cohen's $d=0.17$ ], compared to those who did not. A linear model was fitted to assess the association between participant group, anti-cholinergic medications, daily nicotine consumption, and risk of drug problems on HRV, which demonstrated that participant group was a statistically significant predictor $(t=2.4, p=0.02)$. A one-way ANOVA revealed a main effect of group on $\operatorname{HRV}[\mathrm{F}(2,233)=13.2, p \leq 0.001$, $\left.\eta^{2} p=0.1\right]$. Post hoc pairwise comparisons (Bonferroni corrected) revealed that the HC group had significantly higher values in high frequency HRV than SZ $(p \leq 0.001$; Cohen's $d=-0.91)$ and BD ( $p=0.03$; Cohen's $d=-0.46)$. There was no significant difference in HRV between the SZ and BD groups ( $p=0.069$; Cohen's $d=-0.43$ ).

To account for the potential effects of outliers (Fig. 2A) on these results, a robust ANOVA (Wilcox, 2011) was performed. Outcomes from this ANOVA ( $F=7.08, p=0.002)$ and posthoc tests were similar $(\mathrm{HC}>\mathrm{SZ}, p=0.006$; $\mathrm{HC}>\mathrm{BD}, p=0.04$; $\mathrm{BD}>\mathrm{SZ}, p=0.1$ ), indicating that potential outliers did not unduly influence the original result. A Bayesian ANOVA revealed considerable relative evidence for the alternative hypothesis $\left(\mathrm{BF}_{10}=4606.9\right)$. Posthoc comparisons found considerable evidence for decreased $\mathrm{HRV}$ in SZ compared to HC $\left(\mathrm{BF}_{10}=5536.5\right)$, moderate evidence for decreased HRV in BD compared to $\mathrm{HC}\left(\mathrm{BF}_{10}=6.6\right)$ but modest evidence for decreased $\mathrm{HRV}$ in $\mathrm{SZ}$ compared to $\mathrm{BD}\left(\mathrm{BF}_{10}=1.3\right)$.

Meta-analytically synthesizing data from our previous work revealed similar outcomes, with a statistically significant difference in HRV between SZ and HC $\left(g=-0.69, \tau^{2}=0.03, I^{2}=46.1 \%\right.$, $p<0.0001$, Supplementary Fig. 1a) and BD and HC $(g=-0.45$, $\tau^{2}=0, I^{2}=0 \%, p=0.0003$, Supplementary Fig. 1b). Meta-analysis did not reveal a significant difference between SZ and BD groups $\left(g=-0.25, \tau^{2}=0.0001, I^{2}=0.2 \%, p=0.11\right.$, Supplementary Fig. 1c). A meta-analytic Bayes factor for the comparison of HRV between SZ and BD groups indicated that there was 2.38 times more evidence for the null hypothesis relative to the alternative hypothesis.

Mean levels of all PANSS variables were higher in the SZ group, compared to the BD group (Table 1 and Figs. 2B-E). A one-way ANOVA revealed main effects of patient group on all variables of the PANSS, including PANSS total $\left[\mathrm{F}\left(1,84=37.6, p \leq 0.001, \eta^{2} \mathrm{p}=0.31\right]\right.$, positive symptoms $\left[\mathrm{F}(1,85)=36.8, p \leq 0.001, \eta^{2} \mathrm{p}=0.3\right]$, negative symptoms $\left[\mathrm{F}\left(1,84=30, p \leq 0.001, \eta^{2} \mathrm{p}=0.26\right]\right.$, and general symptoms $[\mathrm{F}$ $\left.(1,85)=18, p \leq 0.001, \eta^{2} p=0.17\right]$. For the Global functioning scores, mean levels of both GAF-S and GAF-F were higher in the BD group compared to the SZ group (Fig. $2 \mathrm{~F}$ and G). One-way ANOVAs revealed a main effect of patient group on GAF-S $[\mathrm{F}(1,85)=5.42, p=0.02$, $\left.\eta^{2} \mathrm{p}=0.06\right]$ and GAF-F scores $\left[\mathrm{F}(1,84)=7.17, p=0.01, \eta^{2} \mathrm{p}=0.08\right]$. There was no significant difference in YMRS total score between patient groups $\left[\mathrm{F}(1,85)=0.06, p=0.81, \eta^{2} p=0.001\right.$; Fig. $\left.2 \mathrm{H}\right]$.

\subsection{Associations between $H R V$ and disease severity}

Table 2 and Fig. 3 display the relationships between HRV and disease severity levels. The PANSS total score was significantly correlated with HRV ( $r=-0.23, p=0.03)$. For the PANSS subdomains, the only significant correlation with HRV was as found with the general symptom score $(r=-0.32, p=0.003)$. Positive correlations were found between HRV and both GAF symptom $(r=0.41, p \leq 0.001)$ and function $(r=0.42, p<0.001)$ scores. There was also a significant negative relationship between YRMS score and HRV $(r=-0.25$, $p=0.018$ ). All nominally statistically significant values from bivariate association tests (i.e., $p<0.05$ ) in Table 2 remained significant after FDR-adjustment.

To assess the role of potential covariates on the association between 

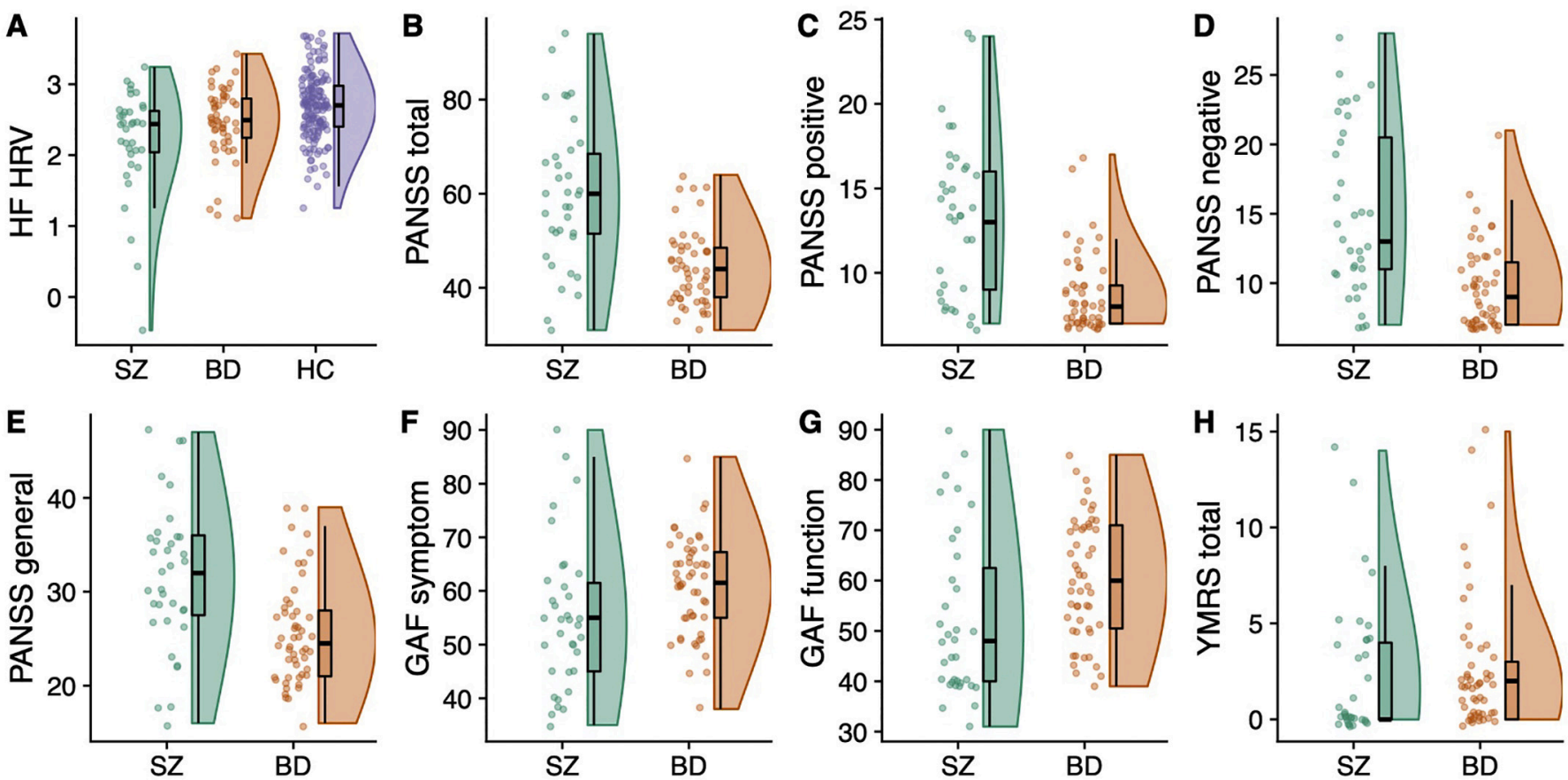

Fig. 2. HRV and clinical variables across diagnostic groups. Raincloud plots visualize raw jittered data, probability density via split-half violin plots, and key summary statistics via overlaid boxplots. High frequency heart rate variability (HF HRV) values are log transformed. SZ $=\mathrm{Schizophrenia;}$ BD $=\mathrm{Bipolar}$ disorder; $\mathrm{HC}=$ Healthy control. PANSS = positive and negative syndrome scale; GAF = global assessment of functioning; YMRS = Young mania rating scale.

disease severity measures and HRV, linear models were fitted that included the following predictors: disease severity measures, age, BMI, anticholinergic medication status, sex, daily nicotine consumption, and risk of drug problems. The PANSS total score $(t=-2.27$, $p=0.02626)$, PANSS general score $(t=-2.97, p=0.004)$, GAF symptom $(t=3.7, p>0.001)$, GAF function $(t=3.53, p=0.001)$, and YRMS scores $(t=-2.1, p=0.04)$ were statistically significant at an uncorrected $p$-value threshold level. All remained significant at FDRcorrected threshold levels, except for the YRMS score. This suggests that these severity scores are associated with HRV, accounting for age, sex, BMI, anticholinergic medication status, daily nicotine consumption, and risk of drug problems. All disease severity coefficients from these models are presented in Table 2 and results for all coefficients for each model are presented in Supplementary tables 1-7.

For a follow-up analysis to help rule out the possible influence of anxiety and depression severity on GAF symptom, GAF function, and YRMS scores, additional models were fitted that included anxiety and depression subscores from the PANSS (i.e., G2 and G6 scores, respectively). These analyses revealed that GAF symptom $(t=3.2$, $p=0.003)$, GAF function ( $t=2.2, p=0.03$ ), and YRMS scores $(t=-2.14, p=0.037)$ were associated with HRV, accounting for age, sex, BMI, anxiety, depression, anticholinergic medication status, daily nicotine intake, and risk of drug problems (Supplementary tables 8-10). These results remained statistically significant after FDR correction for three tests.

\section{Discussion}

Our analyses revealed lower HRV in patients compared to healthy controls, with no significant difference in HRV between the SZ and BD groups, consistent with our previous work. Moreover, within patients, we observed that reduced HRV was associated with higher disease severity, as assessed by the PANSS and GAF. These associations remained when covarying for age, sex, BMI, drug use, nicotine use, and anticholinergic medication status. Our results, suggesting significantly reduced HRV in patients with SZ and BD compared to healthy controls, are in line with two recent large-scale meta-analyses (Clamor et al., 2016; Faurholt-Jepsen et al., 2017), However, we did not find any significant difference between the two clinical groups, supporting previous suggestions of a similar HRV-profile and pathological autonomic

Table 2

The relationship between HRV and clinical variables

\begin{tabular}{|c|c|c|c|c|c|c|c|c|}
\hline \multirow[b]{2}{*}{ Group } & \multirow[b]{2}{*}{$\mathrm{n}$} & \multicolumn{3}{|c|}{ Bivariate associations } & \multicolumn{4}{|c|}{ Regression coefficients } \\
\hline & & $r$ & CI lower & CI upper & $p$ & $\beta$ & $t$ & $p$ \\
\hline PANSS total & 86 & -0.23 & -0.42 & -0.02 & $0.03^{\mathrm{a}}$ & -0.01 & -2.27 & $0.026^{\mathrm{a}}$ \\
\hline PANSS negative & 86 & -0.1 & -0.3 & 0.12 & 0.37 & -0.01 & -0.71 & 0.479 \\
\hline PANSS positive & 87 & -0.16 & -0.354 & 0.058 & 0.153 & -0.03 & -1.98 & 0.052 \\
\hline PANSS general & 87 & -0.32 & -0.49 & -0.11 & $0.003^{\mathrm{a}}$ & -0.03 & -2.97 & $0.004^{\mathrm{a}}$ \\
\hline GAF symptom & 87 & 0.41 & 0.21 & 0.57 & $<0.001^{\mathrm{a}}$ & 0.02 & 3.7 & $<0.001^{\mathrm{a}}$ \\
\hline GAF function & 86 & 0.42 & 0.23 & 0.58 & $<0.001^{\mathrm{a}}$ & 0.02 & 3.53 & $0.001^{\mathrm{a}}$ \\
\hline YMRS total & 87 & -0.25 & -0.44 & -0.05 & $0.018^{\mathrm{a}}$ & -0.04 & -2.1 & 0.04 \\
\hline
\end{tabular}

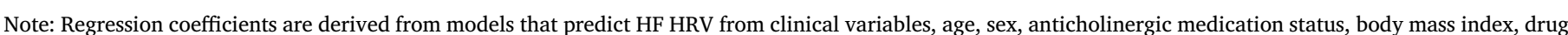

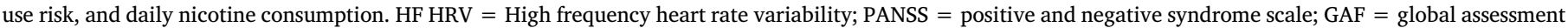
of functioning; YMRS = Young mania rating scale.

a Statistically significant using FDR corrected $p$-value thresholds. 

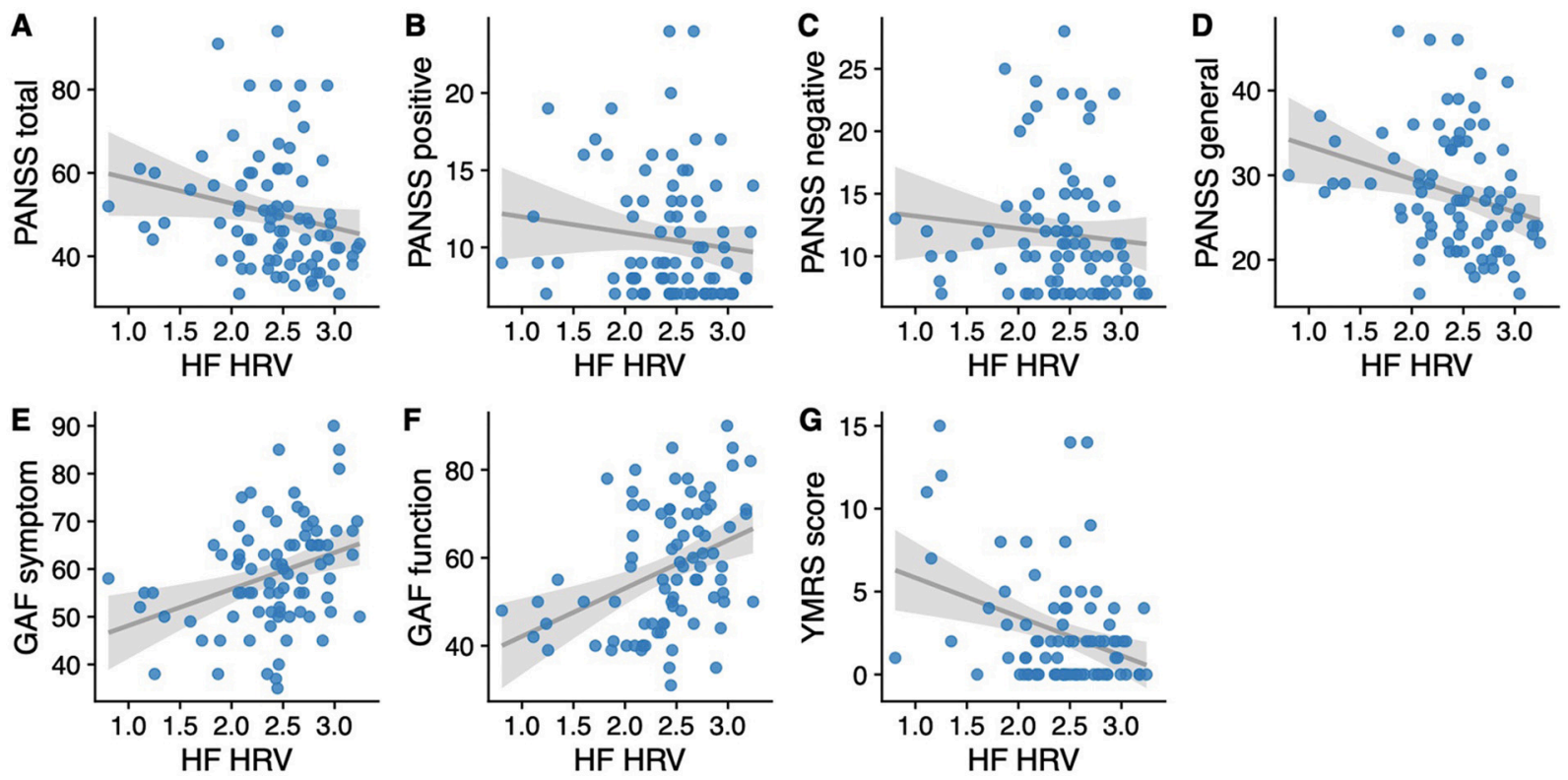

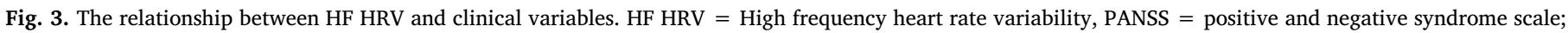
$\mathrm{GAF}=$ global assessment of functioning; YMRS $=$ Young mania rating scale.

dysfunction in these disorders. As such, our results provide added evidence for autonomic dysfunction as a potential shared feature across psychotic disorders. These findings further highlight the need for cardiometabolic screening of patients with $\mathrm{SZ}$ and $\mathrm{BD}$, who, at the group level, are at increased risk of CVD comorbidity and reduced life expectancy (Hennekens et al., 2005; Weiner et al., 2011); a risk that may be partly mediated by disturbed autonomic functioning (Thayer et al., 2010).

There are several biological mechanisms which can account for the co-occurrence of autonomic nervous system dysfunction and psychosis spectrum disorders, including genetics (Ripke et al., 2014), prenatal adversities (Kim et al., 2015), inflammatory mechanisms (Noto et al., 2016; Ripke et al., 2014), accelerated aging (Koutsouleris et al., 2014), and microvascular abnormalities (Uranova et al., 2010), which can influence both cardiovascular and brain health. Together, these factors potentially underlie the link between reduced HRV and severe mental illness. While psychotropic medications can certainly increase the risk of cardiometabolic issues, younger drug-naïve individuals and firstdegree relatives of individuals with psychosis spectrum disorders also demonstrate cardiometabolic abnormalities (Ryan et al., 2003). Indeed, in the present analysis we observed reductions in HRV in patients with psychosis spectrum disorders even when accounting for psychotropic medications that are thought to reduce HRV.

Several previous studies have investigated the relationship between HRV parameters and disease severity in SZ and BD with inconclusive results. Some findings suggest that more severe psychotic symptoms in general are modestly associated with reduced HRV (Bar et al., 2008), whereas others report no associations with positive or negative symptoms (Jindal et al., 2009). Other studies have reported significant negative correlations between negative symptoms and HRV (Quintana et al., 2016b; Valkonen-Korhonen et al., 2003). In contrast to these previous findings, we found no statistically significant association between HRV and negative symptom severity. A potential explanation for this could be that the patient sample in this study is larger than that of our previous study examining HRV in both SZ and BD (Quintana et al., 2016b). Alternatively, the relatively low negative symptom severity scores (Leucht et al., 2019) and the use of three-factor model instead of a five-factor model in this sample (Wallwork et al., 2012) may have also contributed to this result. Positive symptoms have generally not been associated with reduced HRV (Kim et al., 2011; Montaquila et al., 2015;
Quintana et al., 2016b; Valkonen-Korhonen et al., 2003), which is consistent with the present results. Significant positive correlations were found between HRV and both the symptom and functioning domain of the GAF. Importantly, this relationship did not appear to be influenced by age, depression, anxiety, BMI, sex, drug use, or medications with anticholinergic properties.

In contrast to most studies utilizing the PANSS to assess disease severity in psychotic disorders, the present findings imply a negative correlation between HRV and general disease severity. Thereby, our current findings offer a novel perspective on the link between autonomic dysfunction and disease severity in psychotic disorders. Of note, one of the measures indexed by the general symptom domain of the PANSS is executive functioning deficits (Kay et al., 1987), which are behavioural characteristics that have previously been associated with autonomic dysfunction and reduced HRV (Thayer and Lane, 2000). The relationship between autonomic dysfunction and increased severity of general symptoms is further supported by the positive correlation between HRV and GAF scores. In other words, patients who exhibited higher GAF scores (i.e., superior functioning) tended to have higher HRV. We also found that higher levels of manic symptoms (measured by the YRMS) were significantly associated with lower HRV. While the result of this significance test did not survive correction for multiple tests, this outcome is consistent with prior research in unmedicated patients (Chang et al., 2014). The presence of higher YRMS scores in the SZ group could be confounded by the presence of positive psychotic symptoms, so these scores may not be comparable with those in the BD group. Moreover, as the average YRMS score for the BD group of 2.56 was quite low, this suggests that this group was relatively asymptomatic compared to a typical sample of individuals with $\mathrm{BD}$, at least at the time of testing. While the use of mood stabilizers may have reduced manic symptoms, mood stabilizer use did not markedly influence group differences in HRV or the relationship between symptom severity and HRV.

The current findings point to autonomic dysfunction as a shared feature across psychotic disorders, and that reduced vagally-mediated HRV is linked to elements of more severe psychopathology. However, the overlap in HRV between the different groups was substantial, and even highly significant group differences may disguise considerable between-subject heterogeneity within groups. With the common aim of improving clinical prediction and decision making for individual 
patients, more advanced models based on individually predicted deviations from an expected normative reference may provide a valuable framework for moving the field from group-based analysis to inference on the individual level (Wolfers et al., 2018).

Some points regarding specific study limitations should be noted. First, the present study did not have a sufficient sample size to reliably assess differences in HRV between SZ and BD subtypes. Thus, it is unknown whether a potential influence exerted by a particular diagnostic subtype had an effect on the results. Second, data involving psychopharmacological treatment were not available from all patients (Table 1), meaning that there might be hidden confounds in this regard. However, the available data indicated that medication use did not have a considerable impact on HRV in patients. Third, the study did not include a common dedicated scale indexing the levels of current depression severity, which is related to HRV (Kemp et al., 2010). However, HRV was still associated with GAF function and symptom scores when accounting for subscale measures of anxiety and depression from the PANSS. Finally, although participants had some time to habituate to the testing environment, the collection of ECG during EEG data collection may have been stressful for some participants. It is plausible that patients get more anxious in a testing situation compared to controls, potentially leading to an even further decrease in HRV. However, participants' HRV was evaluated based on a "vanilla" condition, which has been found to be effective in reducing anticipation in experimental settings and in obtaining stable baseline values (Jennings et al., 1992). While these conditions may have reduced anxiety, they did not represent a true resting condition, in which participants are instructed to sit (or lie supine) for a short time-period while cardiovascular data is collected. Thus, the present approach limits the direct comparison with other studies that use a true resting state condition to collect cardiovascular data.

In conclusion, significantly lower HRV was found in individuals with SZ or BD compared to healthy individuals, without any significant difference between the two patient groups. Thus, the present results provide further support for the emerging notion of shared features between SZ and BD, which warrants additional investigation. Lower parasympathetic activity was associated with higher disease severity in patient groups. In addition, the findings indicate better psychosocial functioning in patients with higher HRV. As such, the findings suggest that a similar underlying mechanism may mediate autonomic nervous system dysregulation in both SZ and BD, and that HRV may be a valuable tool as an objective biological marker of disease severity and cardiometabolic risk in these disorders.

Supplementary data to this article can be found online at https:// doi.org/10.1016/j.pnpbp.2020.110108.

\section{Declaration of Competing Interest}

O.A.A. has received speaker's honorarium from Lundbeck and is a consultant to HealthLytix. T.E. received speaker's honoraria from Lundbeck and Janssen Cilag. The other authors have no conflicts of interest to declare.

\section{Acknowledgements}

This research was supported by an Excellence Grant from the Novo Nordisk Foundation to D.S.Q. (NNF16OC0019856), the Research Council of Norway (223273, 249795), the South-Eastern Norway Regional Health Authority (2014097, 2016083), the European Research Council under the European Union's Horizon 2020 research and Innovation program (ERC StG, Grant 802998) and CoMorMent (Grant 847776). T.E. was funded by a research grant from the Norwegian South-East Health Authorities (2015078), the Ebbe Frøland foundation, and a research grant from Mrs. Throne-Holst. This article was posted to the Open Science Framework preprint server prior to submission https://osf.io/upj3f/.

\section{References}

Akselrod, S., Gordon, D., Ubel, F.A., Shannon, D.C., Berger, A.C., Cohen, R.J., 1981 Power spectrum analysis of heart rate fluctuation: A quantitative probe of beat-tobeat cardiovascular control. Science 213, 220-222.

Allen, M., Poggiali, D., Whitaker, K., Marshall, T.R., Kievit, R.A., 2019. Raincloud plots: a multi-platform tool for robust data visualization. Wellcome Open Research. https:// doi.org/10.12688/wellcomeopenres.15191.1.

Alvares, G.A., Quintana, D.S., Hickie, I.B., Guastella, A.J., 2016. Autonomic nervous system dysfunction in psychiatric disorders and the impact of psychotropic medications: A systematic review and meta-analysis. J. Psychiatry Neurosci. 41, 89-104. https://doi.org/10.1503/jpn.140217.

Appelhans, B., Luecken, L., 2006. Heart rate variability as an index of regulated emotional responding. Rev. Gen. Psychol. 10, 229-240. https://doi.org/10.1037/1089-2680. 10.3.229.

Bar, K.J., Wernich, K., Boettger, S., Cordes, J., Boettger, M.K., Loffler, S., Kornischka, J., Agelink, M.W., 2008. Relationship between cardiovagal modulation and psychotic state in patients with paranoid schizophrenia. Psychiatry Res. 157, 255-257.

Benarroch, E.E., 1993. The central autonomic network: Functional organization, dysfunction, and perspective. Mayo Clin. Proc. 68, 988-1001.

Berntson, G.G., Stowell, J.R., 1998. ECG artifacts and heart period variability: Don't miss a beat!. Psychophysiology 35, 127-132.

Berntson, G.G., Bigger, J.T., Eckberg, D.L., Grossman, P., Kaufmann, P.G., Malik, M., Nagaraja, H.N., Porges, S.W., Saul, J.P., Stone, P.H., van der Molen, M.W., 1997. Heart rate variability: Origins, methods, and interpretive caveats. Psychophysiology 34, 623-648.

Bramon, E., Sham, P.C., 2001. The common genetic liability between schizophrenia and bipolar disorder: A review. Curr. Psychiatry Rep. 3, 332-337.

Camm, A.J., Malik, M., Bigger, J.T., Breithardt, G., Cerutti, S., Cohen, R.J., Coumel, P., Fallen, E.L., Kennedy, H.L., Kleiger, R.E., 1996. Heart rate variability: standards of measurement, physiological interpretation and clinical use. Task Force of the European Society of Cardiology and the North American Society of Pacing and Electrophysiology. Circulation 93, 1043-1065.

Chang, H.-A., Chang, C.-C., Tzeng, N.-S., Kuo, T.B.J., Lu, R.-B., Huang, S.-Y., 2014. Heart rate variability in unmedicated patients with bipolar disorder in the manic phase. Psychiatry Clin. Neurosci. 68, 674-682. https://doi.org/10.1111/pcn.12178.

Clamor, A., Lincoln, T.M., Thayer, J.F., Koenig, J., 2016. Resting vagal activity in schizophrenia: Meta-analysis of heart rate variability as a potential endophenotype. Br. J. Psychiatry 208, 9-16.

Cohen, J., 1988. Statistical Power Analysis for the Behavioural Sciences. Lawrence Earlbaum Assoc, Hillside. NJ.

Farha, J.G., Sher, K.J., 1989. The effects of consent procedures on the psychophysiological assessment of anxiety: A methodological inquiry. Psychophysiology 26, 185-191.

Faul, F., Erdfelder, E., Lang, A.-G., Buchner, A., 2007. G* Power 3: A flexible statistical power analysis program for the social, behavioral, and biomedical sciences. Behav. Res. Methods 39, 175-191.

Faurholt-Jepsen, M., Kessing, L.V., Munkholm, K., 2017. Heart rate variability in bipolar disorder: A systematic review and meta-analysis. Neurosci. Biobehav. Rev. 73, 68-80.

First, M.B., Gibbon, M., 2004. The Structured Clinical Interview for DSM-IV Axis I Disorders (SCID-I) and the Structured Clinical Interview for DSM-IV Axis II Disorders (SCID-II).

Guloksuz, S., Van Os, J., 2018. The slow death of the concept of schizophrenia and the painful birth of the psychosis spectrum. Psychol. Med. 48, 229.

Hattori, S., Kishida, I., Suda, A., Miyauchi, M., Shiraishi, Y., Fujibayashi, M., Tsujita, N., Ishii, C., Ishii, N., Moritani, T., Taguri, M., Hirayasu, Y., 2018. Effects of four atypical antipsychotics on autonomic nervous system activity in schizophrenia. Schizophr. Res. 193, 134-138. https://doi.org/10.1016/j.schres.2017.07.004.

Hennekens, C.H., Hennekens, A.R., Hollar, D., Casey, D.E., 2005. Schizophrenia and increased risks of cardiovascular disease. Am. Heart J. 150, 1115-1121.

Hildebrand, M., 2015. The psychometric properties of the drug use disorders identification test (DUDIT): A review of recent research. J. Subst. Abus. Treat. 53, 52-59. https://doi.org/10.1016/j.jsat.2015.01.008.

Holzman, J.B., Bridgett, D.J., 2017. Heart rate variability indices as bio-markers of topdown self-regulatory mechanisms: A meta-analytic review. Neurosci. Biobehav. Rev. 74, 233-255.

Huang, W.L., Chang, L.R., Kuo, T.B.J., Lin, Y.H., Chen, Y.Z., Yang, C.C.H., 2013. Impact of antipsychotics and anticholinergics on autonomic modulation in patients with schizophrenia. J. Clin. Psychopharmacol. 33, 170-177.

Jennings, J.R., Kamarck, T., Stewart, C., Eddy, M., Johnson, P., 1992. Alternate cardiovascular baseline assessment techniques: Vanilla or resting baseline. Psychophysiology 29, 742-750.

Jindal, R.D., Keshavan, M.S., Eklund, K., Stevens, A., Montrose, D.M., Yeragani, V.K., 2009. Beat-to-beat heart rate and QT interval variability in first episode neurolepticnaive psychosis. Schizophr. Res. 113, 176-180.

Kay, S.R., Flszbein, A., Opfer, L.A., 1987. The positive and negative syndrome scale (PANSS) for schizophrenia. Schizophr. Bull. 13, 261.

Kemp, A.H., Quintana, D.S., 2013. The relationship between mental and physical health: Insights from the study of heart rate variability. Int. J. Psychophysiol. 89, 288-296. https://doi.org/10.1016/j.ijpsycho.2013.06.018.

Kemp, A.H., Quintana, D.S., Gray, M.A., Felmingham, K.L., Brown, K., Gatt, J.M., 2010 Impact of depression and antidepressant treatment on heart rate variability: A review and meta-analysis. Biol. Psychiatry 67, 1067-1074. https://doi.org/10.1016/j. 
biopsych.2009.12.012

Kim, J.H., Ann, J.H., Lee, J., 2011. Relationship between heart rate variability and the severity of psychotic symptoms in schizophrenia. Acta Neuropsychiatr. 23, 161-166.

Kim, D.R., Bale, T.L., Epperson, C.N., 2015. Prenatal programming of mental illness: Current understanding of relationship and mechanisms. Curr. Psychiatry Rep. 17, 5. https://doi.org/10.1007/s11920-014-0546-9.

Knapp, M., Mangalore, R., Simon, J., 2004. The global costs of schizophrenia. Schizophr. Bull. 30, 279-293.

Koutsouleris, N., Davatzikos, C., Borgwardt, S., Gaser, C., Bottlender, R., Frodl, T., Falkai, P., Riecher-Rössler, A., Möller, H.-J., Reiser, M., Pantelis, C., Meisenzahl, E., 2014. Accelerated brain aging in schizophrenia and beyond: A neuroanatomical marker of psychiatric disorders. Schizophr. Bull. 40, 1140-1153. https://doi.org/10.1093/ schbul/sbt142.

Koval, P., Ogrinz, B., Kuppens, P., Van den Bergh, O., Tuerlinckx, F., Sütterlin, S., 2013. Affective instability in daily life is predicted by resting heart rate variability. PLoS One 8, e81536.

Krabbendam, L., Myin-Germeys, I., De Graaf, R., Vollebergh, W., Nolen, W.A., Iedema, J., Van Os, J., 2004. Dimensions of depression, mania and psychosis in the general population. Psychol. Med. 34, 1177-1186.

Laursen, T.M., 2011. Life expectancy among persons with schizophrenia or bipolar affective disorder. Schizophr. Res. 131, 101-104.

Leucht, S., Barabássy, Á., Laszlovszky, I., Szatmári, B., Acsai, K., Szalai, E., Harsányi, J., Earley, W., Németh, G., 2019. Linking PANSS negative symptom scores with the Clinical Global Impressions Scale: Understanding negative symptom scores in schizophrenia. Neuropsychopharmacology 44, 1589-1596. https://doi.org/10.1038/ s41386-019-0363-2.

Lichtenstein, P., Yip, B.H., Björk, C., Pawitan, Y., Cannon, T.D., Sullivan, P.F., Hultman, C.M., 2009. Common genetic determinants of schizophrenia and bipolar disorder in Swedish families: A population-based study. Lancet 373, 234-239.

Love, J., Mair, P., 2018. Walrus: Robust Statistical Methods.

Montaquila, J.M., Trachik, B.J., Bedwell, J.S., 2015. Heart rate variability and vagal tone in schizophrenia: A review. J. Psychiatr. Res. 69, 57-66.

Morey, R.D., Rouder, J.N., Jamil, T., Urbanek, S., Forner, K., Ly, A., 2018. BayesFactor: Computation of Bayes Factors for Common Designs.

Noto, C., Ota, V.K., Santoro, M.L., Gouvea, E.S., Silva, P.N., Spindola, L.M., Cordeiro, Q., Bressan, R.A., Gadelha, A., Brietzke, E., Belangero, S.I., Maes, M., 2016. Depression, cytokine, and cytokine by treatment interactions modulate gene expression in antipsychotic naïve first episode psychosis. Mol. Neurobiol. 53, 5701-5709. https://doi. org/10.1007/s12035-015-9489-3.

Pedersen, G., Hagtvet, K.A., Karterud, S., 2007. Generalizability studies of the global assessment of functioning-split version. Compr. Psychiatry 48, 88-94.

Pedersen, C.B., Mors, O., Bertelsen, A., Waltoft, B.L., Agerbo, E., McGrath, J.J., Mortensen, P.B., Eaton, W.W., 2014. A comprehensive nationwide study of the incidence rate and lifetime risk for treated mental disorders. JAMA Psychiatry 71, 573-581. https://doi.org/10.1001/jamapsychiatry.2014.16.

Porges, S.W., 2011. The Polyvagal Theory: Neurophysiological Foundations of Emotions, Attachment, Communication, and Self-Regulation, 1st ed. W. W. Norton \& Company, New York.

Quintana, D.S., 2016. Statistical considerations for reporting and planning heart rate variability case-control studies. Psychophysiology 54, 344-349. https://doi.org/10. 1111/psyp.12798.

Quintana, D.S., Heathers, J.A., 2014. Considerations in the assessment of heart rate variability in biobehavioral research. Emot. Sci. 5, 805. https://doi.org/10.3389/ fpsyg.2014.00805.

Quintana, D.S., Williams, D.R., 2017. Bayesian alternatives for common null-hypothesis significance tests in psychiatry: A non-technical guide using JASP. BMC Psychiatry 18, 178. https://doi.org/10.1186/s12888-018-1761-4.

Quintana, D.S., Alvares, G.A., Heathers, J.A., 2016a. Guidelines for Reporting Articles on Psychiatry and Heart rate variability (GRAPH): Recommendations to advance research communication. Transl. Psychiatry 6, e803. https://doi.org/10.1038/tp. 2016.73.

Quintana, D.S., Westlye, L.T., Kaufmann, T., Rustan, Ø., Brandt, C.L., Haatveit, B., Steen, N.E., Andreassen, O.A., 2016b. Reduced heart rate variability in schizophrenia and bipolar disorder compared to healthy controls. Acta Psychiatr. Scand. 133, 44-52. https://doi.org/10.1111/acps.12498.

Ripke, S., Neale, B.M., Corvin, A., Walters, J.T., Farh, K.-H., Holmans, P.A., Lee, P., BulikSullivan, B., Collier, D.A., Huang, H., Pers, T.H., Agartz, I., Agerbo, E., Albus, M., Alexander, M., Amin, F., Bacanu, S.A., Begemann, M., Belliveau, R.A., Bene, J., Bergen, S.E., Bevilacqua, E., Bigdeli, T.B., Black, D.W., Bruggeman, R., Buccola, N.G., Buckner, R.L., Byerley, W., Cahn, W., Cai, G., Campion, D., Cantor, R.M., Carr, V.J., Carrera, N., Catts, S.V., Chambert, K.D., Chan, R.C., Chan, R.Y., Chen, E.Y., Cheng, W., Cheung, E.F., Chong, S.A., Cloninger, C.R., Cohen, D., Cohen, N., Cormican, P., Craddock, N., Crowley, J.J., Curtis, D., Davidson, M., Davis, K.L., Degenhardt, F., Del Favero, J., Demontis, D., Dikeos, D., Dinan, T., Djurovic, S., Donohoe, G., Drapeau, E., Duan, J., Dudbridge, F., Durmishi, N., Eichhammer, P., Eriksson, J., Escott-Price, V., Essioux, L., Fanous, A.H., Farrell, M.S., Frank, J., Franke, L., Freedman, R., Freimer, N.B., Friedl, M., Friedman, J.I., Fromer, M., Genovese, G., Georgieva, L., Giegling, I., Giusti-Rodríguez, P., Godard, S., Goldstein, J.I., Golimbet, V., Gopal, S., Gratten, J., de Haan, L., Hammer, C., Hamshere, M.L., Hansen, M., Hansen, T., Haroutunian, V., Hartmann, A.M., Henskens, F.A., Herms, S., Hirschhorn, J.N., Hoffmann, P., Hofman, A., Hollegaard, M.V., Hougaard, D.M., Ikeda, M., Joa, I., Julià, A., Kahn, R.S., Kalaydjieva, L., Karachanak-Yankova, S., Karjalainen, J., Kavanagh, D., Keller, M.C.,
Kennedy, J.L., Khrunin, A., Kim, Y., Klovins, J., Knowles, J.A., Konte, B., Kucinskas, V., Kucinskiene, Z.A., Kuzelova-Ptackova, H., Kähler, A.K., Laurent, C., Lee, J., Lee, S.H., Legge, S.E., Lerer, B., Li, M., Li, T., Liang, K.-Y., Lieberman, J., Limborska, S., Loughland, C.M., Lubinski, J., Lönnqvist, J., Macek, M., Magnusson, P.K., Maher, B.S., Maier, W., Mallet, J., Marsal, S., Mattheisen, M., Mattingsdal, M., McCarley, R.W., McDonald, C., McIntosh, A.M., Meier, S., Meijer, C.J., Melegh, B., Melle, I., Mesholam-Gately, R.I., Metspalu, A., Michie, P.T., Milani, L., Milanova, V., Mokrab, Y., Morris, D.W., Mors, O., Murphy, K.C., Murray, R.M., Myin-Germeys, I., MüllerMyhsok, B., Nelis, M., Nenadic, I., Nertney, D.A., Nestadt, G., Nicodemus, K.K., Nikitina-Zake, L., Nisenbaum, L., Nordin, A., O'Callaghan, E., O’Dushlaine, C., O’Neill, F.A., Oh, S.-Y., Olincy, A., Olsen, L., Van Os, J., Pantelis, C., Papadimitriou, G.N., Papiol, S., Parkhomenko, E., Pato, M.T., Paunio, T., Pejovic-Milovancevic, M., Perkins, D.O., Pietiläinen, O., Pimm, J., Pocklington, A.J., Powell, J., Price, A., Pulver, A.E., Purcell, S.M., Quested, D., Rasmussen, H.B., Reichenberg, A., Reimers, M.A., Richards, A.L., Roffman, J.L., Roussos, P., Ruderfer, D.M., Salomaa, V., Sanders, A.R., Schall, U., Schubert, C.R., Schulze, T.G., Schwab, S.G., Scolnick, E.M., Scott, R.J., Seidman, L.J., Shi, J., Sigurdsson, E., Silagadze, T., Silverman, J.M., Sim, K., Slominsky, P., Smoller, J.W., So, H.-C., Spencer, C.C.A., Stahl, E.A., Stefansson, H., Steinberg, S., Stogmann, E., Straub, R.E., Strengman, E., Strohmaier, J., Stroup, T.S., Subramaniam, M., Suvisaari, J., Svrakic, D.M., Szatkiewicz, J.P., Söderman, E. Thirumalai, S., Toncheva, D., Tosato, S., Veijola, J., Waddington, J., Walsh, D., Wang, D., Wang, Q., Webb, B.T., Weiser, M., Wildenauer, D.B., Williams, N.M., Williams, S., Witt, S.H., Wolen, A.R., Wong, E.H., Wormley, B.K., Xi, H.S., Zai, C.C., Zheng, X., Zimprich, F., Wray, N.R., Stefansson, K., Visscher, P.M., Adolfsson, R., Andreassen, O.A., Blackwood, D.H., Bramon, E., Buxbaum, J.D., Børglum, A.D., Cichon, S., Darvasi, A., Domenici, E., Ehrenreich, H., Esko, T., Gejman, P.V., Gill, M., Gurling, H., Hultman, C.M., Iwata, N., Jablensky, A.V., Jönsson, E.G., Kendler, K.S., Kirov, G., Knight, J., Lencz, T., Levinson, D.F., Li, Q.S., Liu, J., Malhotra, A.K., McCarroll, S.A., McQuillin, A., Moran, J.L., Mortensen, P.B., Mowry, B.J., Nöthen, M.M., Ophoff, R.A., Owen, M.J., Palotie, A., Pato, C.N., Petryshen, T.L., Posthuma, D., Rietschel, M., Riley, B.P., Rujescu, D., Sham, P.C., Sklar, P., St Clair, D., Weinberger, D.R., Wendland, J.R., Werge, T., Daly, M.J., Sullivan, P.F., O’Donovan, M.C., 2014. Biological insights from 108 schizophrenia-associated genetic loci. Nature 511, 421-427. https://doi.org/10.1038/nature13595.

Rouder, J.N., Speckman, P.L., Sun, D., Morey, R.D., Iverson, G., 2009. Bayesian t tests for accepting and rejecting the null hypothesis. Psychon. Bull. Rev. 16, 225-237.

Ryan, M.C.M., Collins, P., Thakore, J.H., 2003. Impaired fasting glucose tolerance in firstepisode, drug-naive patients with schizophrenia. Am. J. Psychiatry 160, 284-289. https://doi.org/10.1176/appi.ajp.160.2.284.

Schwarzer, G., 2019. General Package for Meta-Analysis.

Selker, R., Love, J., Dropmann, D., 2018. The "Jamovi" Analyses.

Simonsen, C., Sundet, K., Vaskinn, A., Birkenaes, A.B., Engh, J.A., Færden, A., Jónsdóttir, H., Ringen, P.A., Opjordsmoen, S., Melle, I., 2009. Neurocognitive dysfunction in bipolar and schizophrenia spectrum disorders depends on history of psychosis rather than diagnostic group. Schizophr. Bull. 31, 73-83.

Spitzer, R.L., Williams, J.B., Kroenke, K., Linzer, M., Verloin deGruy, F., Hahn, S.R., Brody, D., Johnson, J.G., 1994. Utility of a new procedure for diagnosing mental disorders in primary care: The PRIME-MD 1000 study. JAMA 272, 1749-1756.

Thayer, J.F., Lane, R.D., 2000. A model of neurovisceral integration in emotion regulation and dysregulation. J. Affect. Disord. 61, 201-216.

Thayer, J.F., Yamamoto, S.S., Brosschot, J.F., 2010. The relationship of autonomic imbalance, heart rate variability and cardiovascular disease risk factors. Int. J. Cardiol $141,122-131$.

Tzimos, A., Samokhvalov, V., Kramer, M., Ford, L., Gassmann-Mayer, C., Lim, P., Eerdekens, M., 2008. Safety and tolerability of oral paliperidone extended-release tablets in elderly patients with schizophrenia: A double-blind, placebo-controlled study with six-month open-label extension. Am. J. Geriatr. Psychiatry 16, 31-43. https://doi.org/10.1097/JGP.0b013e31815a3e7a.

Uranova, N.A., Zimina, I.S., Vikhreva, O.V., Krukov, N.O., Rachmanova, V.I., Orlovskaya, D.D., 2010. Ultrastructural damage of capillaries in the neocortex in schizophrenia. World J. Biol. Psychiatry Off. J. World Fed. Soc. Biol. Psychiatry 11, 567-578. https://doi.org/10.3109/15622970903414188.

Valkonen-Korhonen, M., Tarvainen, M.P., Ranta-Aho, P., Karjalainen, P.A., Partanen, J., Karhu, J., Lehtonen, J., 2003. Heart rate variability in acute psychosis. Psychophysiology 40, 716-726.

Wallwork, R.S., Fortgang, R., Hashimoto, R., Weinberger, D.R., Dickinson, D., 2012. Searching for a consensus five-factor model of the positive and negative syndrome scale for schizophrenia. Schizophr. Res. 137, 246-250. https://doi.org/10.1016/j. schres.2012.01.031.

Weiner, M., Warren, L., Fiedorowicz, J.G., 2011. Cardiovascular morbidity and mortality in bipolar disorder. Ann. Clin. Psychiatry Off. J. Am. Acad. Clin. Psychiatr. 23, 40.

Wilcox, R.R., 2011. Introduction to Robust Estimation and Hypothesis Testing. Academic Press, Burlington, MA.

Wolfers, T., Doan, N.T., Kaufmann, T., Alnæs, D., Moberget, T., Agartz, I., Buitelaar, J.K., Ueland, T., Melle, I., Franke, B., Andreassen, O.A., Beckmann, C.F., Westlye, L.T., Marquand, A.F., 2018. Mapping the heterogeneous phenotype of schizophrenia and bipolar disorder using normative models. JAMA Psychiatry 75, 1146-1155. https:// doi.org/10.1001/jamapsychiatry.2018.2467.

Woods, S.W., 2000. The economic burden of bipolar disease. J. Clin. Psychiatry 61, 38-41.

Young, R.C., Biggs, J.T., Ziegler, V.E., Meyer, D.A., 1978. A rating scale for mania: Reliability, validity and sensitivity. Br. J. Psychiatry 133, 429-435. 